\title{
Ethnicity, self-reported illness and use of medical services by the elderly
}

K. BLAKEMORE
B.A., Ph.D.
Department of Applied Social Studies, Coventry (Lanchester) Polytechnic, Priory Street, Coventry CVI 5 FB
Summary

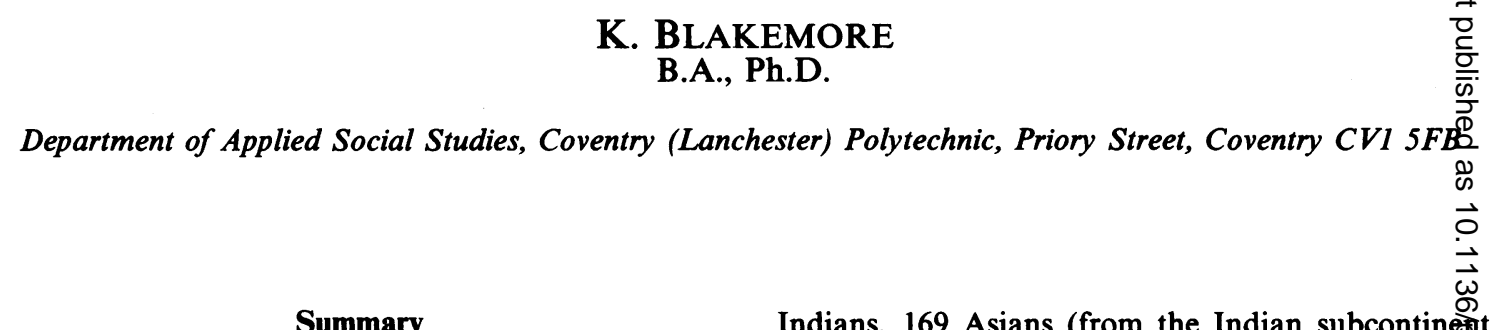

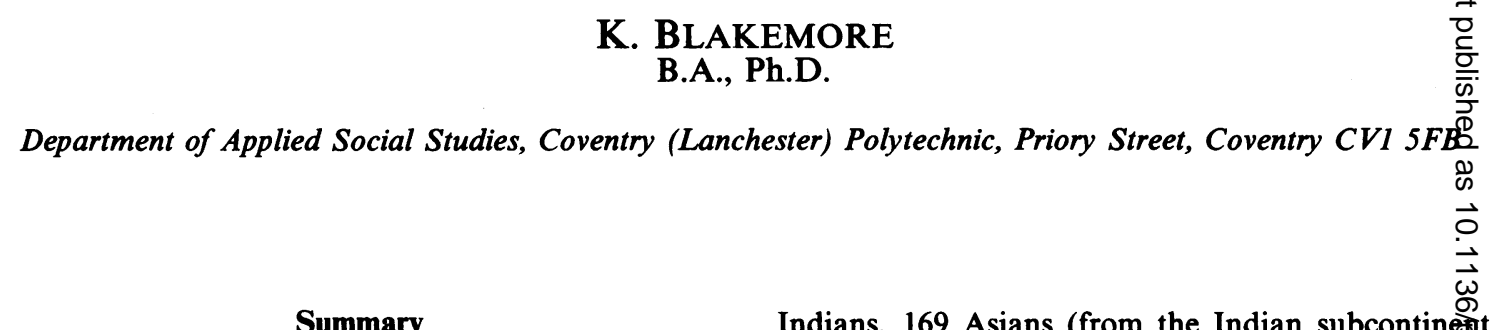

Summary

Analysis of ethnic differences in disease is complicated by the fact that culture has an effect on whether people identify themselves as ill and how often they use medical services. This paper cites evidence to show that use of selected medical services by older members of ethnic groups appears to be high. Although a relatively high amount of disease among minority ethnic groups partly accounts for this, additional explanations - notably, cultural perceptions of doctors and aspects of the ageing migrant's position in society-are suggested.

KEY WORDS: ethnicity, elderly, medical services.

\section{Introduction}

West Indians and Asians over retirement age represent only small minorities within their own ethnic groups in Britain. In the West Midlands, for example, the proportion is only $2.2 \%$ of all those originating from the New Commonwealth and Pakis$\tan$ (Office of Population Censuses and Surveys, 1982). However, those now between 45 years old and retirement age form a more substantial proportion (14\% in the West Midlands) and the number of older Asians and West Indians will rise rapidly.

Initial findings suggest a considerably greater use of medical services by old Asians and West Indians than by old whites living in the same environment (Blakemore, 1982). This paper outlines salient aspects of the social position of the elderly of ethnic minority groups which might influence their attitudes to illness and to medical services.

\section{Methods}

The data are drawn from a survey of 400 men and women over pensionable age living in 4 Birmingham wards in 1979. The survey was designed to discover the social and health needs of the elderly of ethnic minority groups. The sample included 179 West
Indians, 169 Asians (from the Indian subcontinent and from East Africa) and 52 whites. All Faiths One Race (AFFOR), a Birmingham voluntasy agency, commissioned the study (1981) and intê viewing was carried out by a professional market research agency.

Sampling was arranged by the market researeh firm which identified random starts for each interviewer, who then called at every fourth household to interview any retired person in the West Indian and Asian categories. A smaller sample of white pensiogers was then taken, again on a random basis in tife selected wards. In retrospect, it is clear that a larger sample of whites could have been taken, and, order to make a better comparison with the relateeby young ethnic minority groups, the white sañiple could have been stratified to include a larger sampe of 'young' elderly. In the AFFOR sample, 78\% of the Asians and $85 \%$ of the West Indians, but only $35 \%$ if the whites, were found to be aged between 60 and क्षि0 years.

Caution should also be exercised in interpreti啇 results because there is a higher proportion of menin the Asian group (63\%) than in the West Indian (38) or white groups $(33 \%)$. Some of these differences reflect unwillingness of Asian women and of We्हुt Indian men to be interviewed as well as objective differences in the sex ratios of each group. A largescale survey in the West Midlands (Johnson, Cross and Parker, 1982) also shows approximately simiRar proportions of males and females in inner-city Wegst Indian, Asian and white retired groups.

\section{Results}

As the need to consult medical practitioneps generally increases with age (Central Statistical Office, 1980), we might expect the relatively yougg group of retired West Indians and Asians to have seen their general practitioners (GPs) less recentiy than the retired population as a whole, and markedily less than retired inner city whites, among whom is a high number of 'old elderly'. This was not found Jo 
TABLE 1. Percentage of ethnic group that had consulted a general practitioner

\begin{tabular}{|c|c|c|c|c|c|c|c|c|c|}
\hline \multirow[b]{2}{*}{ When GP last seen } & \multicolumn{3}{|c|}{ Asians } & \multicolumn{3}{|c|}{ West Indians } & \multicolumn{3}{|c|}{ Whites } \\
\hline & Women & Men & Total & Women & Men & Total & Women & Men & Total \\
\hline $\begin{array}{l}n \\
\text { Within last month }\end{array}$ & $\begin{array}{l}62 \\
66\end{array}$ & $\begin{array}{r}107 \\
72\end{array}$ & $\begin{array}{c}169 \\
70^{*}\end{array}$ & $\begin{array}{l}111 \\
75 \dagger\end{array}$ & $\begin{array}{l}68 \\
59\end{array}$ & $\begin{array}{c}179 \\
69^{*}\end{array}$ & $\begin{array}{l}35 \\
48\end{array}$ & $\begin{array}{l}17 \\
65\end{array}$ & $\begin{array}{l}52 \\
53\end{array}$ \\
\hline $\begin{array}{l}\text { Not within last month, } \\
\text { but within last year } \\
\text { Longer/never }\end{array}$ & $\begin{array}{l}24 \\
10\end{array}$ & $\begin{array}{r}21 \\
7\end{array}$ & $\begin{array}{r}22 \\
8\end{array}$ & $\begin{array}{r}21 \\
4\end{array}$ & $\begin{array}{l}28 \\
13\end{array}$ & $\begin{array}{r}23 \\
8\end{array}$ & $\begin{array}{l}26 \\
26\end{array}$ & $\begin{array}{l}18 \\
17\end{array}$ & $\begin{array}{l}23 \\
24\end{array}$ \\
\hline
\end{tabular}

This refers to when the respondent's general practitioner was last seen for medical purposes (dated from interview). ${ }^{*} P<0 \cdot 05$ (compared with whites); $\nmid P<0.05$ (compared with West Indian men).

Source: AFFOR (1981).

be the case. The proportion of old Asians and West Indians who had seen their GPs within the previous 12 months (Table 1) was significantly higher than among old whites $(P<0.05)$.

Old Asian men were no more likely to have recently seen their GPs than Asian women, but there is a significant difference between West Indian men and women $(P<0.05)$ in terms of visits during the previous month; it is West Indian women who account for that group's high proportion of recent visits.

Apart from GP consultations, the AFFOR survey also looked into frequency of hospitalization and use of out-patient services during the year before interview. Old Asians use hospital services significantly less than West Indians $(P<0.001)$, though about the same as by whites. However, Asian respondents reported serious illnesses and chronic complaints about as often as West Indians. Some old Asians could be avoiding or delaying hospital treatment, suggesting a need to introduce the kind of health advisory services for Asians described by Forrest and Sims (1982).

\section{Discussion}

That ethnic differences in common diseases occur as a result of combinations of genetic and environmental influences is hardly in question. American evidence (Lawton, 1980) confirms that the health of older blacks and other disadvantaged minorities is usually poorer than that of old whites living in similar environments. Poverty, below-average working conditions and ethnic differences in diet could contribute to the existence of such objective differences in morbidity and mortality rates. However, such inequalities do not mean that cultural influences on use of medical services are unimportant. First, cultural attitudes to illness and medical practitioners could boost GP consultations by the ethnic minority elderly over and above an objectively higher morbidity rate among this group. Second, the appearance of differences in use of hospital services between
Asians and West Indians shows that cultural differences play a part within the broad category of 'ethnic minority elderly' despite, in this case, approximately similar amounts of reported illnesses.

The significance of cultural factors is also illustrated by the perceived role of medical practitioners among old Asians and West Indians. Doctors' advice is readily sought, partly because their role is clearly identifiable and respected, and partly because medical practice in less developed countries has developed along western lines-with the exception that access to doctors in those countries is much more restricted. In Britain, old Asians and West Indians enjoy relatively unrestricted access to GPs. West Indians often cited British medical services as a reason for staying; for a few, access to medical services is the sole reason. The significance of medical consultations for old West Indians is illustrated by the value they place on seeking second opinions. This could stem from traditions in the West Indies, where it is commonly accepted that-if the patient can afford it-overstretched, hospital-based services should be supplemented by private consultations, though old Asians, whose countries of origin share similar kinds of inequality in medical provision, do not seem to seek second opinions as often.

More generally, the role of the migrant contains problems which undoubtedly affect some West Indians and Asians and which could play a part in causing them to seek medical attention more often than old whites. There is the problem, for example, of not feeling emotionally rooted in the society in which one lives, and which perhaps one had once intended to leave on retirement. AFFOR found that, for economic and other reasons, very few old Asians or West Indians make definite plans to return, but this does not mean that most are happily adjusted to old age in Britain; rather, some feel trapped in a society they have very mixed feelings about. While many do see positive aspects to a retirement in Britain (for example, medical services or domestic conveniences), most of these are material things which do not guarantee personal happiness. It must also be re- 
membered that the majority of old Asians and West Indians have had to accept relatively low-paid work in Britain; this may lower a sense of satisfaction or achievement in old age and can erode self-esteem.

Thus, being a migrant and black adds considerably to the stresses of ageing, even if these factors do not equally affect every old Asian or West Indian. Finally, it should not be assumed that most of the elderly of minority ethnic groups will be cared for, or their morale sustained, by the communities around them. Already, two-fifths of old West Indians in Birmingham live alone and, as this is a relatively young group, the proportion is likely to rise considerably in the near future. Though nearly all old Asians, on the other hand, live in large households of six or more, not all are surrounded by close relatives. A quarter of old Asians living in Birmingham have no close relatives in Britain; they may be living in houses with friends or distantly related people, but such relationships do not guarantee the care usually provided by close relatives.

\section{Conclusion}

Though differences in use of medical services must partly be accounted for by objective differences in morbidity rates between ethnic groups and the sexes of each group, cultural factors provide complementary explanations. This paper can do no justice to the complex interrelationships between illness, culture and decisions to seek medical attention; nor has any attempt been made to break down the crude categories of 'Asian' and 'West Indian'. However, some provisional suggestions have been made about the ways in which old Asians' and West Indians' social background might influence their views of medicipe. The insecurity of the role of the ageing migrapt, which can lower morale and possibly threaten hea has also been discussed. It would seem important fot only to continue to study ethnic differences gुn occurrence of common organic diseases, but alsonto extend medical research into ethnic group patterns? mental illness and confusion in old age, especially.as the number of Asians and West Indians reaching the 'old old' stage will rise rapidly over the nex decades.

\section{References}

All Faiths For One RACE (1981) Elderly of Minority Eth Groups. Published by AFFOR, Birmingham.

BLAKEMORE, K. (1982) Health and illness among the elderly of minority ethnic groups living in Birmingham. Health Trends,94, 69.

Central Statistical Office (1980) Social Trends, No. $\overrightarrow{d 0}$, H.M.S.O

FORREST, D. \& SIMS, P. (1982) Health advisory services and कhe immigrant. Health Trends, 14, 10.

Johnson, M., Cross, M. \& PARKer, R. (1982) Unpublished conference paper, Institute of British Geographers.

LAwTON, M.P. (1980) Environment and Aging. Brooks/Cola terey, California.

Office of Population Censuses AND Surveys (1982)를 Census County Reports (West Midlands), H.M.S.O. 